\title{
Do education groups help diabetics and their parents?
}

\author{
A F HACKETT, ${ }^{*}$ S COURT, ${ }^{*} \mathrm{~J}$ N S MATTHEWS, $\dagger$ C McCOWEN, $\ddagger$ AND J M PARKIN* \\ Departments of ${ }^{*}$ Child Health and $†$ Medical Statistics, The Medical School, Newcastle upon Tyne and \\ $\ddagger$ Department of Paediatrics, The Friarage Hospital, Northallerton
}

SUMmARY The importance of education in the management of diabetes is recognised but has rarely been assessed in children. In a longitudinal controlled study we have examined the effect of a programme of education on the knowledge, diet, and concentration of glycated haemoglobin $A_{1 c}$ in a group of diabetics. The programme took the form of two packages of education each consisting of four weekly meetings, in which small groups of parents and older children were led in a discussion of different aspects of diabetes. Only one of the 119 families who began the study failed to complete it. Family knowledge about diabetes improved as a result of the programme, although this was poorly retained in the fathers. A trend to improvement in several aspects of diet was noted but did not reach significance. A significant fall in glycated haemoglobin $A_{1 c}$ was apparent seven months after the education in children aged 11 years and over. Those whose initial control was poor improved most. We conclude that such meetings should be considered as a useful adjunct to regular diabetic clinics.

There are three aims of the treatment of a child with diabetes: normal metabolism (in the belief that this will reduce short and long term morbidity), ${ }^{1}$ satisfactory growth, and as normal a lifestyle as is possible for the patient and family. Achieving these aims, however, is a complex process that makes great demands on a family and so there are many stages at which management may be less than perfect.

In 1985 an audit of all children with diabetes at five clinics on Tyneside and Teeside was undertaken to determine which aspects of management could be improved. Knowledge about diabetes and practical skills were found to be very variable and diet too was less than optimal. ${ }^{2} 3$ Of the factors measured that independently correlated with the child's glycated haemoglobin $A_{1 c}$, only the family's knowledge about diabetes was apparently amenable to change. More diabetic children than controls were perceived by their parents to have behavioural problems. This was less apparent in those with better knowledge about diabetes. ${ }^{4}$ These findings suggested the need for a method of improving knowledge about diabetes that would not generate anxiety.

There have been several studies of the effects of educational programmes on the care of diabetics and most of these have found some benefits; at least in the short term. ${ }^{5-8}$ There have been few large scale studies of children, however, the effect of reinforcing a basic programme of education has not been assessed, the follow up has often been either erratic or short term, and some educational inputs have been complex and costly. This study was designed to create and evaluate a structured programme of education that could be run with limited resources at any clinic. It was based upon meetings at which the professionals enabled small groups of families to share their knowledge and experience of diabetes.

\section{Patients and methods}

Patients attending children's diabetic clinics in Newcastle, Gateshead, North Tees, and Middlesbrough were invited to take part. Most had previously taken part in the audit study and some who had transferred to adult clinics were still included. The volunteers were stratified according to the child's age, sex, and diabetic control (concentration of glycated haemoglobin $A_{1 c}$ ) and the most recent occupation of the father (socioeconomic group). They were then randomly allocated to one of four experimental cohorts that were balanced for these variables. Each cohort was subdivided into four, taking into account the addresses of the families, to give groups of manageable size (six to 10 families) for the educational programme.

All families were assessed at the beginning of the 
study and those in cohorts 1 and 2 were invited to the primary educational package. All families were reassessed eight months later and then those in cohort 1 were invited to a second, reinforcement, educational package and those in cohort 3 to the primary package for the first time. All families were assessed again at the end of the study, 16 months after the start, after which those in cohort 4 , the controls, were invited to the primary educational package (table 1). The study began in May 1985 when one group from cohort 1 or 2 and one from cohort 3 or 4 were assessed. Two more groups were assessed each calendar month thereafter, the final assessments being in July 1987. Throughout the study all the intervals between assessments were constant.

Each assessment was similar and consisted of a home visit by AFH at which standard social information was obtained, and a capillary blood sample taken, using the Unistep procedure (Ciba Corning), for the estimation of glycated haemoglobin $\mathbf{A}_{1 \mathrm{c}}$ concentrations. All the blood samples were analysed in one laboratory by gel electrophoresis after removal of the labile fraction. ${ }^{9}$ The normal range for adults by this method is $5 \cdot 0-7 \cdot 5 \%$. Knowledge was assessed using one of five multiple choice questionnaires designed for this study, ${ }^{10}$ which was chosen at random and given to children aged 11 years and older and their parents. A dietary diary for the three days before the visit was completed by either parent or child. This record of what the child ate was checked and quantified at the home visit. ${ }^{3}$ The fat and carbohydrate intakes were expressed as the proportion of total energy, and fibre intake was also calculated in relation to energy intake. Those families scheduled for invitation to meetings were given a printed timetable and were encouraged to attend. At the routine clinic appointment closest to each assessment a random blood sample was requested for estimation of $\mathrm{C}$ peptide concentration from every child unless already known to be $C$ peptide negative $(<0.18 \mathrm{nmol} / \mathrm{l})$.

The content of the educational packages has been described elsewhere. ${ }^{11}$ Each package consisted of four, one and a half hour, discussions facilitated by two members of the research team and had a printed worksheet to maintain consistency. The four meetings in the primary package covered background and management, insulin, diet, and practical problems. The four reinforcement meetings were designed to complement and to follow the primary package and consisted of a quiz, tests of skill, problem solving discussion groups, and a showing of the video 'The way of life' sponsored by Nordisk UK. An individual who was present for at least two sessions of a series was deemed to have attended the meetings and the family 'attended' if any family member met this criterion. There was an extra assessment of knowledge by a further multiple choice questionnaire at the end of the final meeting in each series.

The data were analysed separately for families with children aged under and over 11 years because only the older children completed the multiple choice questionnaires and were encouraged to attend the meetings. Furthermore, from the age of 11 years most children would be expected to be making a considerable independent contribution to the management of their diabetes.

The results of the multiple choice questionnaires were analysed separately for mothers, fathers, and children. A linear model, ${ }^{12}$ which eliminated the between person variation, was used to test whether there was any difference between the baseline score for an individual and the scores achieved (a) immediately after education, (b) after a lag of seven months, and (c) after a lag of 15 months (with no intervening education). The tests for these results were done hierarchically as there was no basis for thinking that there may have been an effect at 15 months with no corresponding effect at seven months. The model also allowed a check to be made for the presence of systematic effects upon questionnaire scores from any other cause; none was found.

The dietary and glycated haemoglobin $A_{1 c}$ results were analysed by analysis of covariance. The covariates considered were the initial level of the variable being investigated, socioeconomic group, age, sex,

Table 1 Overall study design

\begin{tabular}{|c|c|c|c|c|c|c|c|c|c|c|c|c|c|c|c|c|c|c|c|}
\hline & \multirow{2}{*}{$\begin{array}{l}\text { No of } \\
\text { families } \\
(n=119)\end{array}$} & \multicolumn{18}{|c|}{ Month } \\
\hline & & 1 & 2 & 3 & 4 & 5 & 6 & 7 & 8 & 9 & 10 & 11 & 12 & 13 & 14 & 15 & 16 & 17 & 18 \\
\hline $\begin{array}{r}\text { Cohort } 1 \\
2 \\
3 \\
4\end{array}$ & $\begin{array}{l}32 \\
29 \\
32 \\
26\end{array}$ & $\begin{array}{l}\text { A1 } \\
\text { A1 } \\
\text { A1 } \\
\text { A1 }\end{array}$ & $\begin{array}{l}\text { E1 } \\
\text { E1 }\end{array}$ & & & & & & & $\begin{array}{l}\text { A2 } \\
\text { A2 } \\
\text { A2 } \\
\text { A2 }\end{array}$ & $\begin{array}{l}\text { E2 } \\
\text { E1 }\end{array}$ & & & & & & & $\begin{array}{l}\text { A3 } \\
\text { A3 } \\
\text { A3 } \\
\text { A3 }\end{array}$ & E1 \\
\hline
\end{tabular}

$\mathrm{A} 1=$ initial assessment, $\mathrm{A} 2=$ second assessment, $\mathrm{A} 3=$ final assessment, $\mathrm{E} 1=$ primary educational package, E2=reinforcement package. 
and duration of the diabetes. Only the initial level of the variable under investigation was found to be important.

\section{Results}

One hundred and nineteen families, $46 \%$ of those invited, agreed to take part in the study and completed the first assessment. The second and third assessments were completed by 118 families, although dietary data were not available for two families at the third assessment. This was because of marital problems in one family and extensive hospitalisation of the child in the other. The only family not to complete the study moved from the area. These families with incomplete data were all in different cohorts. There were no significant differences between the children in the different cohorts at the initial assessment apart from a greater proportion of subjects in socioeconomic groups 1 and 2 in cohort 4 (table 2). This was caused by the loss of a small number of families after stratification but before the first assessment.

ATTENDANCE

The primary package $(\mathrm{E} 1)$ was attended by $68 \%$ of

Table 2 Details of children with diabetes in the cohorts at the initial assessment. Results are number or mean (SD)

\begin{tabular}{|c|c|c|c|c|c|}
\hline & \multicolumn{4}{|l|}{ Cohorts } & \multirow[b]{2}{*}{ Total } \\
\hline & 1 & 2 & 3 & 4 & \\
\hline Sex (boys/girls) & $20 / 12$ & $19 / 10$ & $17 / 15$ & $18 / 8$ & $74 / 45$ \\
\hline \multicolumn{6}{|l|}{ Socioeconomic group } \\
\hline $1+2$ & 15 & 9 & 14 & 15 & 53 \\
\hline $3+4$ & 13 & 13 & 14 & 7 & 47 \\
\hline $5+6$ & 3 & 5 & 4 & 3 & 15 \\
\hline $7+8+9$ & 1 & 0 & 0 & 0 & 1 \\
\hline Age (years) & $12 \cdot 7(2 \cdot 9)$ & $11 \cdot 4(3 \cdot 3)$ & $12 \cdot 4(3 \cdot 6)$ & $11 \cdot 7(3 \cdot 3)$ & $12 \cdot 1(3 \cdot 3)$ \\
\hline Glycated haemoglobin $A_{l c}(\%)$ & $11 \cdot 1(2 \cdot 7)$ & $11 \cdot 2(1 \cdot 7)$ & $11 \cdot 0(2 \cdot 3)$ & $10 \cdot 8(2 \cdot 1)$ & $11 \cdot 1(2 \cdot 2)$ \\
\hline \multicolumn{6}{|l|}{ C peptide } \\
\hline$\leqslant 0.18 \mathrm{nmol} / 1$ & 27 & 25 & 31 & 23 & 106 \\
\hline$<0 \cdot 18 \mathrm{nmol} / 1$ & 1 & 1 & 0 & 1 & 3 \\
\hline Duration of diabetes (years) & $4 \cdot 6(2 \cdot 9)$ & $5.9(2 \cdot 8)$ & $5 \cdot 3(3 \cdot 2)$ & $5 \cdot 0(3 \cdot 1)$ & $5 \cdot 2(3.0)$ \\
\hline
\end{tabular}

Table 3 Scores on multiple choice questionnaire of families who attended the meetings to which they were invited (cohorts 1-3), of those not invited (cohort 4), and of those who although invited did not attend. Results are mean (number of questionnaires completed)

\begin{tabular}{|c|c|c|c|c|c|c|}
\hline Score at: & $\begin{array}{l}\text { Initial } \\
\text { assessment }(A 1)\end{array}$ & $\begin{array}{l}\text { After } \\
\text { education (E1) }\end{array}$ & $\begin{array}{l}\text { Second } \\
\text { assessment (A2) }\end{array}$ & $\begin{array}{l}\text { After } \\
\text { education }(E 1 \text { or } E 2)^{*}\end{array}$ & $\begin{array}{l}\text { Final } \\
\text { assessment (A3) }\end{array}$ & $\begin{array}{l}\text { After } \\
\text { education (E1) }\end{array}$ \\
\hline \multicolumn{7}{|l|}{ Mothers: } \\
\hline Cohort 1: & $18(24)$ & $21(22)$ & $19(24)$ & $21(23)^{*}$ & $20(23)$ & \\
\hline $2:$ & $15(19)$ & $21(18)$ & $20(19)$ & $19(14)$ & $18(19)$ & \\
\hline 3: & $16(14)$ & & $15(14)$ & & $17(13)$ & \\
\hline 4: & $19(25)$ & & $20(25)$ & & $20(25)$ & $23(20)$ \\
\hline Did not attend: & $15(32)$ & & $15(30)$ & & $16(32)$ & \\
\hline \multicolumn{7}{|l|}{ Fathers: } \\
\hline Cohort 1: & $17(23)$ & $20(21)$ & $16(23)$ & $19(21)^{*}$ & $17(22)$ & \\
\hline $2:$ & $12(14)$ & 19 (13) & $12(13)$ & 19 (12) & $15(12)$ & \\
\hline 3: & $15(13)$ & & $16(13)$ & & $17(13)$ & \\
\hline 4: & $15(24)$ & & 17 (22) & & $17(23)$ & $20(19)$ \\
\hline Did not attend: & $14(29)$ & & $14(29)$ & & $14(27)$ & \\
\hline \multicolumn{7}{|c|}{ Children with diabetes: } \\
\hline Cohort 1: & $11(18)$ & $15(18)$ & $15(19)$ & $17(20)^{*}$ & $16(19)$ & \\
\hline $2:$ & $10(12)$ & $14(9)$ & $13(12)$ & & $12(12)$ & \\
\hline 3: & $11(8)$ & & $12(8)$ & $15(8)$ & $13(9)$ & \\
\hline 4: & $10(20)$ & & $11(19)$ & & $12(20)$ & $17(17)$ \\
\hline Did not attend: & $10(23)$ & & $10(24)$ & & $14(27)$ & \\
\hline
\end{tabular}

*Score after reinforcement.

A typical between subject standard deviation was $5 \cdot 5$. 
those families invited and the reinforcement (E2) by $77 \%$. Attendance was not related to the age or sex of the child, glycated haemoglobin $\mathrm{A}_{1 \mathrm{c}}$ concentration, socioeconomic group, or duration of the diabetes. British Diabetic Association (BDA) members, however, were more likely to attend (48 families of the $64 \mathrm{BDA}$ members attended compared with 15 of the 29 non-members invited). ${ }^{11}$

\section{SCORES ON MULTIPLE CHOICE QUESTIONNAIRE}

Table 3 shows the mean scores on the multiple choice questionnaire of the mothers, fathers, and children in families that attended the meetings (cohorts 1-3), of those who were not invited to meetings (cohort 4), and of those invited but who did not attend. The analysis of these data showed strong evidence that the educational package increased the mean questionnaire scores of the mothers, fathers, and children ( $p<0.001$ in all cases) in the short term. For the mothers and children there was also strong evidence that the mean questionnaire scores were still raised seven months after the education $(p<0.001$ in both cases); there was no evidence of this for the fathers $(p>0 \cdot 05)$. There was a suggestion that the mean questionnaire scores of the mothers and children were increased at 15 months after the education $(\mathrm{p}<0 \cdot 10)$, but as this effect can only be assessed for cohort $2(n=29)$, the test has low power. The mean increases in questionnaire scores, adjusted for the differences between individuals, with $95 \%$ confidence intervals, are shown in table 4 . There was no evidence that the effect on the questionnaire scores of the reinforcement package, preceeded by the primary package, was different from that achieved by the primary education package alone $(\mathrm{p}>0 \cdot 05)$.

In general, the scores of the mothers and children changed in a way similar to that which might have been anticipated from the study design; an appreciable rise in the short term followed by a slow decay. The scores of the fathers, however, showed no evidence of sustained improvement. There was no evidence of an effect of socioeconomic group on change in questionnaire scores. Generally, those

Table 4 Adjusted mean increases from baseline in scores on multiple choice questionnaire as a result of being invited to the meetings (95\% confidence interval)

\begin{tabular}{lllllll}
\hline & Mothers & \multicolumn{2}{l}{ Fathers } & $\begin{array}{l}\text { Children with } \\
\text { diabetes }\end{array}$ \\
\hline $\begin{array}{l}\text { Immediate } \\
\text { At } 7\end{array}$ & 3.2 & $(2.2$ to 4.2$)$ & 2.4 & $(1.1$ to 3.7$)$ & 4.9 & $(3.6$ to 6.2$)$ \\
$\quad$ months & 1.8 & $(1.7$ to 4.2$)$ & $-0.3(-1.5$ to 1.0$)$ & 2.9 & $(1.7$ to 4.2$)$ \\
$\begin{array}{c}\text { At } 15 \\
\text { months }\end{array}$ & $1.3(-1.9$ to 4.6$)$ & $1.8(-0.7$ to 4.2$)$ & $1.9(-0.4$ to 4.1$)$ \\
\hline
\end{tabular}

families who were invited to the meetings but did not attend started and finished the study with the least favourable values.

\section{DIET}

Those children whose families had attended both sets of meetings ended with the lowest fat intakes and the highest intakes of carbohydrate and fibre (table 5). For the children under and over 11 years of age, however, the analysis of covariance indicated that the small changes in diet were not significant. The changes in the dietary components are summarised in table 6 .

Table 5 Dietary intake of children with diabetes whose families attended the meetings to which they were invited (cohorts 1-3), of those not invited (cohort 4), and those who although invited did not attend. Results are means

\begin{tabular}{llll}
\hline No & \multicolumn{2}{l}{ Assessment } & \\
\cline { 2 - 3 } & Initial (A1) & Second (A2) & Final $(A 3)$ \\
\hline
\end{tabular}

\begin{tabular}{lllll}
\hline Fat (\%): & & & & \\
Cohort 1: & 24 & 41 & 38 & 38 \\
2: & 19 & 41 & 39 & 40 \\
3: & 14 & 41 & 39 & 41 \\
4: & 25 & 40 & 39 & 40 \\
Did not attend: & 34 & 41 & 40 & 41 \\
\multicolumn{1}{l}{ Carbohydrate (\%): } & & & \\
Cohort 1: & 24 & 45 & 46 & 46 \\
2: & 19 & 44 & 47 & 46 \\
3: & 14 & 46 & 46 & 45 \\
4: & 25 & 45 & 46 & 44 \\
Did not attend: & 34 & 44 & 45 & 43 \\
& & & & \\
Fibre (g/MJ): & & & & \\
Cohort 1: & 24 & $2 \cdot 8$ & $2 \cdot 9$ & $2 \cdot 9$ \\
2: & 19 & $2 \cdot 8$ & $2 \cdot 8$ & $2 \cdot 7$ \\
3: & 14 & $2 \cdot 6$ & $2 \cdot 6$ & $2 \cdot 6$ \\
4: & 25 & $2 \cdot 8$ & $3 \cdot 0$ & $2 \cdot 7$ \\
Did not attend: & 34 & $2 \cdot 4$ & $2 \cdot 7$ & $2 \cdot 6$
\end{tabular}

Typical between subject standard deviations were: fat $4.5 \%$, carbohydrate $4 \cdot 5 \%$, and fibre $0 \cdot 8 \mathrm{~g} / \mathrm{MJ}$.

Table 6 Changes in the dietary intake of children with diabetes whose families attended the meetings to which they were invited (cohorts 1-3), of those not invited (cohort 4), and those who although invited did not attend

\begin{tabular}{crrrr}
\hline & No $\begin{array}{l}\text { Mean }(S E) \\
\text { carbohydrate } \\
(\%)\end{array}$ & $\begin{array}{l}\text { Mean }(S E) \\
\text { fat }(\%)\end{array}$ & $\begin{array}{l}\text { Mean }(S E) \\
\text { fibre }(g / M J)\end{array}$ \\
\hline Cohort 1: & 24 & $1.6(0.91)$ & $-2.6(0.99)$ & $0.11(0.148)$ \\
$2:$ & 19 & $1.6(1.11)$ & $-1.2(1.09)$ & $-0.05(0.187)$ \\
$3:$ & 14 & $-1.1(1.08)$ & $-0.4(1.12)$ & $0.03(0.212)$ \\
$4:$ & 25 & $-0.8(0.75)$ & $0.6(0.76)$ & $-0.13(0.181)$ \\
Did not attend: & 34 & $-1.0(0.90)$ & $0.2(0.75)$ & $0.14(0.137)$ \\
\hline
\end{tabular}


CONTROL

Like the scores on the multiple choice questionnaire and dietary results, the pattern of changes in glycated haemoglobin $\mathrm{A}_{1 \mathrm{c}}$ concentration was as expected: cohort 1 finished the study with the lowest mean values (table 7). Analysis of covariance showed no effect of the educational package on the glycated haemoglobin $A_{1 c}$ concentrations of the children aged under 11 years. For all the children aged 11 years and over, whose families were invited to the meetings, the analysis of covariance indicated that the educational package led to marginal improvements in concentrations of glycated haemoglobin $A_{1 c}$. The effect of the education depended upon the initial glycated haemoglobin $A_{1 c}$ concentration of the child (test for non-parallelism, F3;72 $=2 \cdot 40$, $\mathrm{p}=0 \cdot 07$ ). For children who initially had glycated haemoglobin $\mathrm{A}_{1 \mathrm{c}}$ concentrations of 8,12 , and $16 \%$,

Table 7 Glycated haemoglobin $A_{\text {Ic }}$ concentrations (\%) of those children with diabetes whose families attended the meetings (cohorts 1-3), those not invited (cohort 4), and those who although invited did not attend. Results are means

\begin{tabular}{|c|c|c|c|c|}
\hline & \multirow[t]{2}{*}{ No } & \multicolumn{3}{|l|}{ Assessment } \\
\hline & & Initial $(A 1)$ & Second (A2) & Final $(A 3)$ \\
\hline Cohort 1: & 24 & $10 \cdot 9$ & $9 \cdot 5$ & 9.9 \\
\hline $2:$ & 19 & $11 \cdot 5$ & $10 \cdot 9$ & $10 \cdot 9$ \\
\hline 3: & 14 & $10 \cdot 1$ & $11 \cdot 3$ & $10 \cdot 1$ \\
\hline $4:$ & 25 & $10 \cdot 9$ & $10 \cdot 9$ & $10 \cdot 4$ \\
\hline Did not attend: & 34 & $11 \cdot 4$ & $11 \cdot 1$ & $10 \cdot 8$ \\
\hline
\end{tabular}

A typical between subject standard deviation was $2 \cdot 2 \%$.

Table 8 Expected final glycated haemoglobin $A_{\text {Ic }}$ concentration for a selection of initial values. Values are given for children with diabetes aged 11 years and over only: for all families and for those who were invited to the educational packages and did attend

Initial glycated haemoglobin $A_{\text {Ic }}(\%)$

\begin{tabular}{lll}
\hline 8.0 & 12.0 & $16 \cdot 0$
\end{tabular}

All children, whether families attended or not:

$\begin{array}{rrrr}\text { Cohort 1: } & 9.0 & 10 \cdot 5 & 11.9 \\ 2: & 7.7 & 11.3 & 14.9 \\ 3: & 8.8 & 11.2 & 13.8 \\ 4: & 7.8 & 11.2 & 14.5\end{array}$

(The residual standard deviation was $1.7 \%$ )

Children whose families attended the meetings:

$\begin{array}{rrr}\text { Cohort 1: } & 9 \cdot 0 & 10 \cdot 5 \\ 2: & 7 \cdot 6 & 11 \cdot 4 \\ 3: & 10 \cdot 6 & 10 \cdot 3 \\ 4: & 7 \cdot 8 & 11 \cdot 2\end{array}$

(The residual standard deviation was $1.6 \%$ ) the final concentrations expected for each of the cohorts are given in table 8 . Values for the other initial values can be found by linear interpolation.

For those children over 11 years whose families actually attended the meetings the analysis of covariance showed a significant effect of education on glycated haemoglobin $A_{1 c}$ concentration ( $F$ $3,53=3 \cdot 58, p=0 \cdot 02 ;$ table 8 ). The low level of attendance in cohort 3 (only 14 of the 32 families attended) may have introduced some bias into this analysis. The effect of the primary package appeared to be of limited duration as at the end of the study cohort 2 was no better than the controls (cohort 4). The cohorts who had received most recent education, either reinforcement (cohort 1) or the primary package (cohort 3 ), did best of all.

\section{Discussion}

This study has shown that a simple educational programme increased the knowledge about diabetes of the mothers, fathers, and children who attended. The improvement in knowledge then decayed (in the fathers very quickly) but an improvement was apparent seven months, and possibly even 15 months, after the programme for mothers and children. The beneficial effects on dietary intake were equivocal but an improvement in concentration of glycated haemoglobin $A_{l c}$ was apparent seven months after the meetings.

The crucial role of education in the management of diabetes is generally recognised. ${ }^{13}$ For the past 30 years many studies have shown poor knowledge about diabetes and its management among patients and the parents of diabetic children. ${ }^{14}$ Organising groups is a logical way to address this problem. Group meetings prevent needless repetition, reduce barriers between doctor and patient, and help patients to share worries, problems, and experiences. Such programmes, however, make unfamiliar demands upon staff and accommodation; there is no agreed syllabus or generally accepted method, and relatively few suitable teaching aids are available. Furthermore the time which parents, children, and staff can give is limited.

The evaluation of educational programmes is also problematical. Glycated haemoglobin $\mathrm{A}_{1 \mathrm{c}}$ gives an objective measure of mean blood glucose over a lengthy period of time but may conceal unacceptable episodes of hyperglycaemia and hypoglycaemia. ${ }^{15} \mathrm{~A}$ successful programme of education may even lead to a modest rise in glycated haemoglobin $A_{\text {Ic }}$ concentration in a small number of diabetics from initially over anxious families. Glycated haemoglobin is therefore an imperfect measure of the success of the management of diabetes. Knowledge 
too cannot be easily assessed; multiple choice questionnaires are usually used but cannot assess practical skills and must be designed and administered with care.$^{16}$ In particular, they may not apply equally to families of different backgrounds. Finally, diet is difficult to measure with both reliability and validity. ${ }^{17}$ In addition, a change in the proportion of energy from fat or carbohydrate of only 1-2 percentage points nevertheless represents a major change in the eating habits and lifestyle of the child and family. Such changes could only be detected with a very large sample size.

Few programmes of education have been evaluated and the results have been inconsistent. ${ }^{14}$ Some have led to improvements in knowledge, control, and diet, and some to no improvements in control despite better knowledge. Several studies, however, have found gains in knowledge and control to be short lived ${ }^{6}$ but all published studies appear to show some benefit for those who took part. Such findings may arise because the association between control and knowledge is complex and mediated by motivation and attitudes and hence compliance. ${ }^{16}$ Compliance with even simple therapeutic regimens is often very poor but nobody is completely non-compliant; patients may comply with only some parts of their regimen and these may change with time. ${ }^{18}$ For children the situation is even more complex as the parents and others are also involved in the management, and their role changes as the child grows. There is a variety of reasons why changes in control or behaviour may not result from an educational programme even if it does improve knowledge. The demonstration of benefits from a practical programme of education is important and suggests that resources would not be wasted if such a programme were organised as an adjunct to regular clinic visits.

Fathers of diabetic children are less knowledgeable about diabetes than mothers. ${ }^{9} 14$ This, together with the finding that the increase in their knowledge decayed so quickly, even for those who were motivated enough to attend the programme, is cause for concern. It suggests that the role of fathers in day to day management is minimal; this imposes excessive responsibility on mothers and sets a poor example to children. We have previously found that more mothers than fathers had seen their family doctors about their 'nerves'. ${ }^{4}$ There is therefore an urgent need for fathers to be encouraged to take a more active role in the management of diabetes.

This educational intervention led to children aged 11 years and over increasing their knowledge about diabetes and improving their control. The improvement in the knowledge of the mothers, however, did not result in better control of the younger children.
These findings suggest that priority should be given to educating children.

Our programme required three hours of staff time per session for between six and 10 families; a similar committment of time as a traditional clinic. If the meetings are presented as another facet of the care of diabetics, and incorporated into regular clinics, an excellent response is likely. Evening meetings, however, have the advantage of enabling both parents to attend and a programme to be followed without disrupting schooling. A 'fathers only' meeting may be valuable. In this study the number of meetings chosen and the intervals were arbitrary. Four weekly meetings appeared to be the most that our families would tolerate in one programme but the confidence necessary to allow forthright discussion developed slowly. An important requirement is to allow 'simple human interaction' to occur in a relaxed non-judgmental but refereed setting for which confidence is essential. ${ }^{19}$

As families are expected to take increasing responsibility for the day to day management of diabetes the need for systematic education and revision of practical skills has grown. These are unlikely to be met efficiently by conventional clinic visits, which are necessary for monitoring the health of the child and family and providing individual advice and trouble shooting. We have shown that even a modest programme of group education can result in tangible benefits and recommend that consideration be given to incorporating it into normal clinical practice.

We thank the paediatricians and physicians on Tyneside and Teeside who allowed us access to their patients and the families who took part. This study was planned with the help of Dr DR Appleton and Professor KGMM Alberti. This study was financed by the British Diabetic Association and assistance was also give by Nordisk - UK

It is anticipated that the educational materials developed during this study will become generally available.

\section{References}

1 Leslie ND. Sperling MA. Relation of metabolic control to complications in diabetes mellitus. J Pediatr 1986;108:491-7.

2 McCowen C. Hackett AF. Court S. Parkin JM. Are families of diabetic children adequately taught? Br Med J 1986;292:1361.

Hackett AF, Court S, McCowen C, Parkin JM. Dietary survey of diabetics. Arch Dis Child 1986;61:67-71.

+ Court S. Sein E. McCowen C. Hackett AF, Parkin JM. Children with diabetes mellitus: perception of their behavioural problems by parents and teachers. Early Hum Dev 1988;16: 245-52.

5 Etzwiler DD. Robb JR. Evaluation of programmed education among juvenile diabetics and their families. Diabetes 1972;21: $967-71$

${ }^{6}$ Korhonen T, Huttunen JK, Aro A, et al. A controlled trial on the effects of patient education in the treatment of insulindependent diabetes. Diabetes Care 1983;6:256-61. 
${ }^{7}$ Lucey D. Wing E. A clinic based educational programme for children with diabetes. Diabetic Medicine 1985:2:292-5.

${ }^{8}$ Marteau TM, Gillespie C. Swift PGF. Evaluation of a weekend group for parents of children with diabetes. Diabetic Medicine 1987:4:488-90.

9 Technical Information Centre. Electrophoresis labile removing hemolizing reagent. Glycosylated hemoglobin set. Essex: Ciba Corning.

${ }^{10}$ McCowen C, Court S, Hackett AF, Parkin JM. An evaluation of multiple choice questionnaire for the assessment of knowlege in diabetic children and their families. Diabetic Medicine 1988;5: 474-488.

${ }^{11}$ Court S, McCowen C. Hackett AF, Parkin JM. Experiences with running a programme of education for diabetic children and their parents. Diabetic Medicine 1989;6:366-8.

12 Seber GAF. The linear hypothesis: a general theory. London: Griffin, 1980.

13 World Health Organisation. WHO expert committee on diabetes mellitus. Second report. (Technical report series 646.) WHO: Geneva, 1980.

14 Bennett Johnson S. Knowledge, attitudes and behaviour: correlates of health in childhood diabetes. Clinical Psychology Reviews 1984;4:503-24.

15 Tattersall RB. World book of diabetes in practice. Vol 2. Oxford: Elsevier, 1986:111-4.

16 Dunn SM, Bryson JM, Hoskins PL, et al. Development of the diabetes knowledge (DKN) scales: forms DKNA, DKNB, and DKNC. Diabetes Care 1984;7:36-41.

17 Hackett AF, Morton S, McCowen C, Court S, Dickson D, Parkin JM. Measurement of food intake in children with diabetes mellitus: a comparison of protein intake and urine nitrogen. Diabetes Res 1987;6:29-32.

18 Rosenstock IM. Understanding and enhancing patient complicance with diabetic regimens. Diabetes Care 1985;8:610-6.

19 Dunn SM. Reactions to educational techniques: coping strategies for diabetes and learning. Diabetic Medicine 1986;3:419-29.

Correspondence and requests for reprints to Professor JM Parkin, Department of Child Health, The Medical School, Framlington Place, Newcastle upon Tyne NE2 4HH.

Accepted 3 January 1989 